\title{
CRITICAL REFLECTIONS ON THE CONCEPT OF MAINTENANCE
}

\author{
Hans LIND $1 \bowtie$ and Henry MUYINGO ${ }^{2}$ \\ ${ }^{1}$ Royal Institute of Technology, School of Architecture and the Built Environment, Department \\ of Real Estate and Construction Management, Brinellvägen 1, Stockholm 100 44, Sweden \\ E-mail: hans.lind@abe.kth.se \\ ${ }^{2}$ Royal Institute of Technology, School of Architecture and the Built Environment, Department \\ of Real Estate and Construction Management, Brinellvägen 1, Stockholm 100 44, Sweden \\ E-mail: henry.muyingo@abe.kth.se
}

Received 26 February 2011; accepted 31 August 2011

\begin{abstract}
The purpose of the paper is to critically evaluate the conceptual distinction between investment and maintenance. The study starts from a number of definitions in the literature and discusses these from the perspective of standard investment theory. The article argues that the standard concept of investment covers all relevant decisions and also puts the focus on the future consequences of decision and not whether it restores an earlier standard or not. The research implications are that investment and maintenance planning need to be analysed together and that the distinction between investment and maintenance is uninteresting from a decision theoretic and resource allocation perspective. The practical implications of the article are that what usually is called investment planning and maintenance planning need to be integrated. The originality in the paper lies primarily in the questioning of the usefulness of the concept of maintenance in a dynamic age where the relation to earlier characteristics and functions becomes less and less interesting. The role of the maintenance concept is now primarily related to various administrative systems (accounting, taxation) but is not so relevant from a forward looking resource allocation perspective.
\end{abstract}

KEYWORDS: Maintenance; Investment; Accounting; Planning; Real estate

\section{INTRODUCTION}

The concept of maintenance is widely used in for example property management but its definition tends to vary not only between authorities but also between companies (SWECO, 2006) and within the same organisation (Gustafson, 2005) and the classification of activities at times changes from year to year depending on how the company would like to account for it (Lind, 2002). A natural reaction to such a situation is to try to clarify the concept of maintenance (Oresten, 1997; Lind, 2002) in relation to nearby concepts as operation and investment.
The strategy in this paper is to start from more basic investment theory, and it is interesting to note that in that context the concept of maintenance is seldom used (see for example Geltner et al., 2007). The explanation for this is very simple: An investment is defined as spending resources today in order to get some kind of "advantage" in the future. By spending resources today the company either gets higher revenues in the future, or reduces future cost. From this perspective every activity that typically is called maintenance is also investment: resources are spent today in order 
to get lower costs in the future (or higher revenue) compared to if the maintenance is not made.

The aim of this paper is therefore to discuss the need and interpretation of the concept of maintenance from the perspective of standard investment theory.

The structure of the paper is as follows. In the next section the perspective of standard investment theory is presented briefly. Before maintenance concepts are discussed in section 4 , there is a short section about investment and maintenance from an accounting and taxation perspective. In section 5 it is argued that the maintenance concept is unnecessary and also misleading if the focus is on efficient decisions today, and an alternative conceptual framework is sketched. Concluding comments can be found in section 6 .

\section{THE BASIC PERSPECTIVE OF INVESTMENT THEORY}

The basic idea in investment theory is that - for a number of reasons - a dollar received today is worth more than a dollar received tomorrow. This is transformed into the fundamental formula where the Net Present Value of a series of expenses and revenues are calculated by discounting the future consequences by a discount factor reflecting the rate of return demanded, which is related to the risk of the project.

The starting point is usually some kind of "investment" $I_{0}$ - a negative cash-flow in "year 0" - and using the formula below it is possible to evaluate whether the investment is profitable or not. This is done through subtracting the initial investment $\left(\mathrm{I}_{\mathrm{o}}\right)$ from the total sum of the present values of the future cash-flows $\left(\mathrm{CF}_{\mathrm{t}}\right)$ giving a net present value (NPV) of the investment, given a certain rate of return demanded $(r)$.

$$
\mathrm{NPV}=-I_{0}+\sum_{1}^{t} \frac{C F_{t}}{(1+r)^{t}}
$$

In property management the cash flows discounted and used to calculate the NPV are the annual net incomes that are received, calculated as the difference between the rental and other related incomes and the total operating, maintenance and other related costs, inclusive of the investment.

There is of course nothing in this theory that says that this "investment" - $\mathrm{I}_{0}$ - has to be large. Repainting a room, or replacing a machine part is formally a decision that has the same structure as a larger investment and is therefore suitable to be analysed within the same framework.

The basic NPV-formula is of course also relevant in discussions about life-cycle aspects (see e.g. Bescherer, 2005 pp. 14 and Lang, 2007). If the framework is applied correctly it will include a life-cycle perspective that takes into account e.g. the remaining value or remaining cost at the end of the period analysed. The analysis can be carried out over the whole life span of a building or a component or for a particular stage. There are some controversies about the usefulness of the NPV-framework if there are option aspects involved, e.g. that a standard investment changes the future possibilities to adjust a building to changing circumstances (see e.g. Gunnelin, 2000), but this will not be discussed any further here.

The conclusion so far is that maintenance should be seen as a sub-category of investment, and the next step is to discuss what can explain why this sub-category exists.

\section{INVESTMENT AND MAINTENANCE FROM THE PERSPECTIVE OF ACCOUNTING AND TAX SYSTEMS}

There are two general "administrative" systems that affect the conceptual structure related to investment: accounting and taxation.

From the perspective of both accounting and taxation it is important to define and measure a yearly result, something that is 
irrelevant from the perspective of investment theory. In order to calculate the yearly result it must be decided which expenses should be activated and depreciated during a number of years and which expenses should be counted as a cost directly. "Investment" from both an accounting and tax perspective is defined as expenses that should be activated as an asset and depreciated over a number of years.

Before the new IFRS-standards accounting rules have focused on minimising the risk for overestimation of the yearly result. One kind of accounting fraud, found e.g. in the famous Enron and Worldcom scandals (see for example Nordlund, 2008, pp. 36, where further references can be found) is to call ordinary costs investment and thereby showing higher profits than the true level. From this perspective we can then define "maintenance" as "investments" that should be treated as a cost and not be activated. A common definition, as will be returned to below, is to call all expenses that are directed at retaining the standard of the object maintenance. Expenses that lead to higher standard than that, or to larger areas, are called investments. As noted in Nordlund (2010) there is often a lack of transparency about how this line is drawn.

From a tax perspective the problem is almost the opposite to that in accounting (see Lind, 2002), as the tax authorities do not want firms to report too low profits by treating all investments as a cost the year that it is made. The tax rules typically focus on forcing firms to activate certain expenses, and spreading the costs over a number of years.

The common feature from both an accounting perspective and a tax perspective is then that what is investment from the perspective of basic investment theory is subdivided into expenses that are activated and then written down over a number of years, and expenses that are treated as a cost the year that they are made. The first type of expenses is then called "investment" while the second type of investment is called "maintenance". The rules are often described in terms of "investment should be activated" and "maintenance should be treated as a cost immediately", but it would be more correct to say that if something should be activated then we call it investment, and if something should be treated as a cost directly we call it maintenance.

There are some interesting changes in the rules and applications in recent years (see for example Nordlund, $2008 \mathrm{ch}$. 3). If the IFRS rules about "fair-value accounting" are applied consistently then there is no longer any need to make a distinction between investment and maintenance. The "cost" a specific year is calculated as the total expenses related to the property minus changes in the value of the properties. If a measure taken leads to a higher value it is automatically "activated", and of course everything that is a (successful) investment in the sense of investment theory - in that it increases future cash flow - will lead to a higher value and therefore we are back with a perspective where all investments according to investment theory are treated as investments. Tax rules however still treat realised and unrealised capital gains differently.

Another accounting principle that avoids the problem of dividing expenses into investment and maintenance is when an investment (in the theoretical sense) is divided into a number of components that are depreciated separately. The whole sum is then activated when a part is replaced or a room repainted, and thus this investment is written down component for component. When a certain component is replaced it is automatically activated and a new period of depreciation follows. In this approach there is no need to make a distinction between investment and maintenance: all expenses with an effect on future cash-flow are treated as an investment that is activated and then written down, some over a long time period and some over a short time period. 
From these arguments we want to draw the following conclusion:

- The division into "investment" and "maintenance" has been central in both accounting theory and tax rules.

- Today there are accounting systems where no such distinction is needed.

A general conclusion is however that whether the distinction between investment and maintenance is important or not from a planning and decision making perspective, must be determined independently of concepts introduced for administrative reasons.

\section{THE CONCEPT OF MAINTENANCE}

\subsection{The standard demarcation of maintenance}

In order to conceptualise maintenance the standard procedure is to demarcate it from its closely related terms, operation and investment. In this section these demarcations are presented and also some of the differences between the maintenance standards AFF 04 and EN 13306:2001 are commented upon. AFF 04 is the standard used by most property and facility management firms and organisations in
Sweden (AFF-definitioner 04). EN 13306:2001 Maintenance Terminology is the one in use internationally.

The definitions of the concepts differ from author to author and between companies (see e.g. Gustafsson, 2005; SWECO, 2006). EN13306:2001 defines only maintenance whereas AFF04 contains the definitions given below of operation and maintenance.

AFF 04 defines operation as "Actions with an expected interval of less than one year that aim at sustaining the function of a manageable object" (AFF-definitioner 04). It is subdivided as shown in Figure 1.

The definition of maintenance in $\mathrm{AFF} 04$ is limited to "Actions aimed at restoring the functions of a managed item, fixture or appliance."

The European standard on maintenance terminology (EN 13306:2001), defines maintenance as "Combination of all technical, administrative and managerial actions during the life cycle of an item intended to retain it in, or restore it to, a state in which it can perform the required function".

Though AFF 04 does not define investment explicitly but the following subdivision is provided (Figure 2):

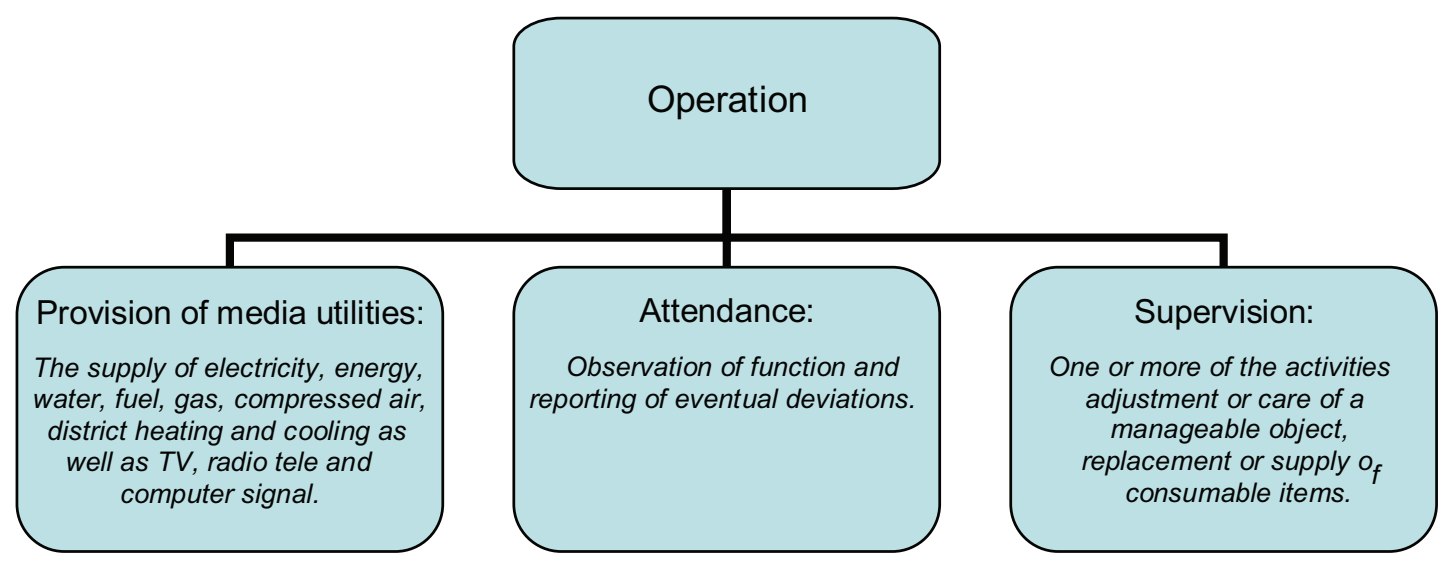

Figure 1. Operation types in AFF 04 


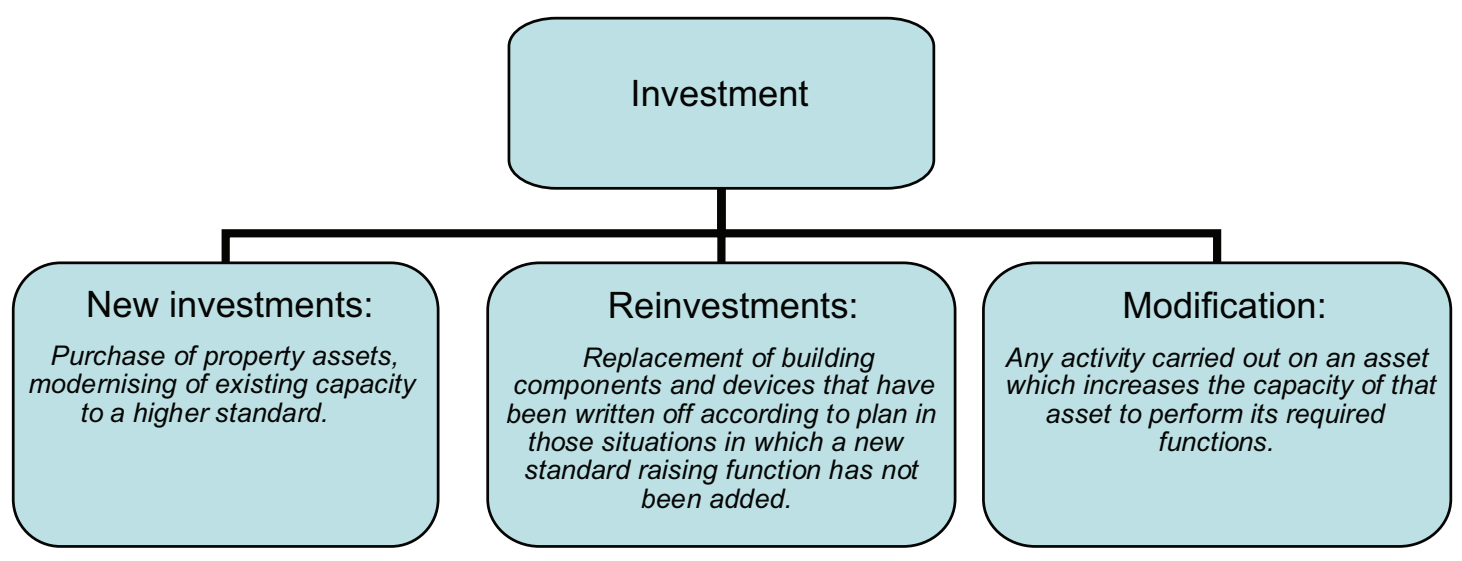

Figure 2. Investment types in AFF 04

\subsection{General comments on the definitions}

The two definitions of maintenance presented above differ somewhat in perspective. AFF 04 implicitly assumes that the technical functions are deteriorating and that maintenance is done to restore the original functions of the systems. According to EN 13306:2001 the phrase "actions intended to retain in a functional state" is also included, which is a somewhat broader concept. Sections of what is called operation in the Swedish terminology are included in the international definition of maintenance Operation is then reduced to cost for utilities, while all supervision, repair and care which aim at either restoring or retaining a function fall under maintenance.

However, there are some common problems, and one is the use of the vague concept of "function". Things can work more or less well, and the fact that an object is in good working condition and to say that it "functions" is, in the end, a decision that is based on views on evaluation of consequences and resources available. This can be illustrated by a roof of a building that leaks a little once every second year or so during both strong winds and rain, but is otherwise not leaking: Does the roof function or not? The distinction between "retain" and "restore" also seems rather dubious in a situation where demands and views on necessary functions change over time.

These problems will, however, lose their importance if the arguments in the next section are accepted.

\section{ALTERNATIVE TO THE CONCEPT OF MAINTENANCE}

\subsection{The central argument}

A central idea in economic theory is that the rational decision maker should be forward looking, weighting the future costs and benefits of a specific decision. This implies that it is irrelevant whether this decision leads to retaining, restoring or improving on the earlier or original standard of the system. Comparing the standard after implementing a certain measure with the standard at some earlier date, says nothing about whether the decision is rational or not, as it is a backward looking description. This is especially true when the point of comparison is some earlier original standard as when maintenance is defined from the perspective of whether it leads to restoring a certain function or not. 
From a forward looking perspective all decisions are unique in the sense that the future consequences are evaluated given the current situations, which are subject to change together with the expected consequences and the evaluation of these consequences. Another way to put this is that it should always be an open question about what the optimal standard for the object is: Should it be kept at the current standard, allowed to deteriorate or should it be improved?

An example is if a component breaks down in a technical system, it will depend on the current situation whether:

- Any action should be taken at all, because maybe the building is soon to be demolished and it can function without the specific function for the remaining time. Perhaps an elevator breaks down, but as there is another, nothing is done to repair the broken one.

- If something should be done, should it be something that increases the standard or not. Maybe the technical development has been such that when a repair should be done, the marginal cost of adding some extra functions is lower than the marginal gain from this increase in the standard. For example when a tap breaks down, the extra cost of replacing it with one that reduces water flow might be very small.

From a decision making perspective a more interesting distinction seems to be between situations where measures should be taken without any special investigation and others where a special investigation should be done. As it takes resources to make a specific evaluation, it can be rational to do certain thing on a routine basis for a certain period of time, e.g. cleaning the corridors once a week, and replacing a light bulb that does not work with a new one of a specific type. But such routine measures need to be evaluated on a regular basis.

\subsection{Basic framework}

The starting point for the discussion is that there is an object under the control of a decision maker. We are of course primarily thinking in terms of a building or a set of buildings, but it can of course just as well be a machine or a set of machines. From the forward looking perspective of investment theory the history of the current situation is of less importance. As discussed above it cannot matter how the current situation relates to an earlier situation and thus concepts like retain and replace are not useful.

What then matters is:

- the current situation,

- the alternative options and predictions about their future costs and benefits,

- the alternative "meta-options":

- how we should collect information about the current situation,

- how actions should be chosen in a certain situation.

\subsubsection{How to keep informed}

Here we have a continuum of opportunities like:

- Automatic surveillance.

- Inspections.

- Waiting until something happens and the user reports this to the maintenance organisation.

The technological development and increasing wage level reduces the relative costs of reliable automatic surveillance and we can therefore expect to see that in more and more situations. On the revenue side, the rationale for investing in surveillance or many inspections is related to the importance of finding eventual problems early. This in turn could be understood in terms of how early information affects the future cost and/or the probability of fixing a problem. When installing new pipes for central heating sensors are for example put in place in order to reduce the costs of finding 
future leaks. We assume that one reason why there are so many surveillance screens in the cock-pit of an airplane is that it is very important to find problems early. However a wellknown problem with automatic surveillance is that if the system signals that something is wrong, there is always a certain probability that it is the surveillance system that is faulty and not the system being monitored.

Waeyenbergh and Pintelon (2004) note that human senses can detect a wide variety of failure conditions which is utilised under what they classify as detection based maintenance. It has a much lower set up cost but it is vulnerable to the subjectivity and experience of persons as some will detect irregularities that will be missed by others.

In extreme cases where for example a part is replaced or servicing carried out according to a schedule intended to reduce the risk of problems to almost zero, there is almost no need to keep oneself informed about how the specific system is working. If there is some rare condition, it will automatically be found when the specific part is replaced or the servicing is done.

\subsubsection{How to make decisions}

We can divide the decisions in a number of categories depending on the amount of resources spent before making the decision.

\section{Extreme case 1}

One extreme is when decisions are made without any special investigation related to the individual case. There are several subcategories:

- Certain measures are taken independent of any specific information about the system like when a filter is always replaced after a certain time period. This is rational in a situation where it is costly to inspect but the predictability of the system is rather high making it possible to know roughly the optimal time in which to take action.
- Certain measures are always taken when specific information generated by the ordinary information systems on a particular condition of the object is reported. An example is when an air-filter is replaced if the system monitoring the quality of the air reports that it is below a certain threshold.

These two cases are what is usually classified as "time-based" and "condition-based" "maintenance", but it should be noted that in the cases above it might, as discussed below, be rational to replace an old part either by a part that has a higher or lower quality.

\section{Extreme case 2}

The other extreme is when a special large scale investigation is done before a decision is taken. Typically when there are a number of unexpected events it is not obvious what the rational thing to do is. The rational decision might also depend on a number of characteristics of the situation, and instead of specifying all these in advance, it can be more economical just to wait and see what happens before deciding on the action to take. This will depend on the specific situation. If the roof is leaking in a new building it might be rather straightforward what to do, but if it leaks in an old building it might be necessary to make a deeper investigation of the future of the building before deciding on the action to take in the case of the roof.

The difference between Case 1 and Case 2 above can be compared to the difference between a complete contract, where everything is regulated in advance and a relational contract where only a problem solving mechanism is specified (see for example Milgrom and Roberts, 1992). Another way to describe the difference between these extreme cases is to focus on who is making the decision about what to do. The more mechanical the decision the more it can be decentralised. If a lot of resources are spent on preparing a decision, then the final 
decision is usually taken on a higher level in the organisation. (There is also a meta-meta level concerning decision-making: How should we make rational decision about how to make rational decisions? Rubinstein (1998) discusses the infinite regress problem in relation to rational decision making: The rational person makes rational decision about how to make decision, but must then also make rational decisions about how to make rational decisions and how to make decisions, etc.).

\subsection{The options and the actions}

From a forward looking perspective the historical standard of the object is irrelevant. The policy options in a certain situation should only be distinguished by how the current standard should be changed.

From this perspective there are a number of possible actions. The following examples might illustrate the options: Suppose there is a problem with the brakes in one of the company cars. One option is to scrap or sell the car and do nothing else: It might be rational to reduce the number of company cars. Or if there is a problem with the radiators in one classroom in a school, it might be rational to close-down the classroom, because there are vacant rooms where the heating is working. Another alternative is of course to repair the brakes and repair the radiators in a way that makes them work roughly as before the failure. But the company may also choose to buy a new car, or replace the heating system with a new one with many new qualities, e.g. automatic adjustments to predict weather conditions.

From a longer time perspective it should always be an open question what to do in a specific situation. Any predetermined strategy needs to be evaluated and adjusted when the situation changes and new options become available. One problem with thinking in terms of maintenance is that it indicates some given long run strategy in relation to historical standards, neglecting that what is rational will constantly change when situations change and new information is available. This is often neglected in optimisation models that help to determine the interval between different measures that maximises reliability, availability and profits.

Some examples of changes that might affect the decision making on what is rational to do are:

- new technologies and new products come on to the market,

- changes in the need of the services that the object produces or changes in the value of the services produced by the object,

- changes in the relative cost of various actions.

\section{CONCLUDING COMMENTS}

The general ideas in this paper can be summarized in the following way:

- From the perspective of investment theory everything that is usually classified as maintenance is also an investment, in the sense that resources are spent today that produce reduced costs or higher benefits in the future compared to if the resources are not spent.

- Maintenance is generally separated from "true" investments by saying that maintenance is a matter of restoring an old function or keeping up an old function. This means that maintenance is defined in relation to historical standards. Rational decision making is however forward looking and the old standard cannot matter.

- From the forward-looking perspective what is especially important is the meta-strategies in terms of how to keep informed and how to make decisions, and the insight that the future is uncertain and that therefore long-run and detailed plans are inefficient. In a longer perspec- 
tive it is always an open question as to whether the standard of an object should be kept in, improved or discarded.

Most attempts to revolutionize a conceptual structure fail, as the perceived advantage of changing the conceptual structure into something that perhaps is more logical does not match the obvious costs of trying to introduce a new way of looking at things. But discussing the fundamental conceptual structure is, as we see it, important in any case, as it makes us see things clearer and also makes us aware of the fact that all conceptual structures change over time. When technology and society changes, the concepts that we need to describe and understand that structure change, and also the way that we structure the problems that we handle. The concept of maintenance is much more suitable in a world where there are smaller changes and where it is believed to be possible to know long in advance what is rational to do. The conceptual structure presented here seems to us more suitable to a society with more rapid changes, and when it almost all the time is an open question what to do with for example a specific building.

On a more basic level the discussion in this article is related both to works concerning framing (e.g. Kahneman and Tversky, 1979) and theories about paradigms (Kuhn, 1962). The common feature is that how we approach and interpret things depend on the concepts we use and that there often are hidden assumptions behind the use of a certain concept.

\section{REFERENCES}

AFF-definitioner 04. [Online] AB Svenska Byggtjänst. Available at: http://aff.byggtjanst.se/ Pages/AllAffDoc.aspx?item=2 [accessed 17 May 2009]

Bescherer, F. (2005) Established life cycle concepts in the business enviroment - introduction and terminology. Helsinki University of Technology, Industrial Engineering and Management, Helsinki.
Geltner, D. M., Miller, N. G., Clayton, J. and Eichholtz, P. (2007) Commercial real estate analysis and investments. UK: Thomson-South Western.

Gunnelin, $\AA$. (2000) Real options in real estate. Doctoral Thesis, ABE-KTH, Stockholm.

Gustafsson, U. (2005) Vad är investering och vad är underhåll? - En inventering av begreppstolkningen $i$ fastighetsbranschen [What is investment and what is maintenance? A stock taking of concept use in the real estate sector]. Masters thesis, BYFA-KTH, Stockholm.

Kahneman, D. and Tversky, A. (1979) Prospect theory: an analysis of decision under risk, Econometrica, 47(2), pp. 263-291. http://dx.doi.org/10.2307/1914185

Kuhn, T. S. (1962) The structure of scientific revolutions. Chicago: University of Chicago Press.

Lang, A. (2007) Sensitivity analysis of life cycle cost calculation. [Online] School of Electrical Engineering. Available at: http://www.ee.kth.se/ $\mathrm{php} /$ modules/publications/reports/2007/IR-EEETK_2007_010.pdf [accessed 12 April 2011]

Lind, H. (2002) Nya principer för avskriuning: En strategi för rätt bokfört värde på offentliga fastigheter [New principles for depreciation: A strategy for the correct bok value of public properties]. Stockholm: Svenska Kommunförbundet.

Milgrom, P. and Roberts, J. (1992) Economics, organisation and management. New Jersey: Prentice Hall Int.

Nordlund, B. (2008) Valuation and performance reporting in property companies according to IFRS. Doctoral Thesis, ABE-KTH, Stockholm.

Nordlund, B. (2010) Need for disclosure regarding property valuations in financial reports according to IFRS, Journal of Property Investment \& Finance, 28(5), pp. 333-353. http://dx.doi.org/10.1108/14635781011069954

Oresten, B. (1997) Rätt begrepp: nomenklatur, definitioner och mätregler för nyckeltal $i$ offentlig fastighetsförvaltning [Correct concept: nomenclature, definitions and measurement in public real estate management]. Stockholm: Svenska Kommunförbundet, UFOS.

Rubinstein, A. (1998) Modeling bounded rationality. London, England: The MIT Press. 
SWECO (2006) Definition och gränsdragning av begreppen - drift, underhåll och investering [Definition and demarcation av concepts, operation, maintenance and investment]. [Online] Samverksforum (Association of government agencies and enterprises engaged in building or managing real estate, buildings and other facilities). Available at: http://www.samverkansforum.nu/samverkansforum/Publika_do-
kument/Publikt_fr_Natverket_forvaltning/Rapport_BegreppDefinitioner_061018.pdf [accessed 11 April 2011]

Waeyenbergh, G. and Pintelon, L. (2004) Maintenance concept development - a case study, International Journal of Production Economics, 89(3), pp. 395-405.

http://dx.doi.org/10.1016/j.ijpe.2003.09.008 